\title{
Differences in priority by age group and perspective: implications for public health education and campaigning in relation to dementia
}

\author{
Irja Haapala, ${ }^{1,2}$ Ashley Carr ${ }^{1}$ and Simon Biggs ${ }^{1,3}$ \\ ${ }^{1}$ University of Melbourne, School of Social and Political Sciences, Melbourne, Victoria, Australia \\ ${ }^{2}$ University of Eastern Finland, Department of Educational Science and Teacher Education, Savonlinna, Finland \\ ${ }^{3}$ Brotherhood of St Laurence, Melbourne, Victoria, Australia
}

Objectives: A shift toward public health responses to dementia, raises questions about the most appropriate approaches to specific population groups. We examined perspective and age as elements in effective campaigning. Implications from the standpoint of the recipient are drawn for public health education and practice.

Design: In-depth semi-structured face-to-face and telephone interview with self-selected participants recruited via adverts, contact with provider organizations and cards placed in retail and service settings. Questions focused on attitudes to dementia and expectations of public campaigning and education.

Setting: Community-dwelling adults were interviewed across five Australian states.

Participants: A total of 111 people from 5 target groups: people with dementia $(n=19)$, carers $(n=28)$, care work and service professionals from healthcare $(n=21)$, social work $(n=23)$ and commercial service professions $(n=20)$ involving people in younger adulthood $(n=13)$, early midlife $(n=23)$, later midlife $(n=54)$, and older age $(n=21)$.

Measurements: All interviews were transcribed and analyzed thematically by three researchers, reaching consensus before coding and further analysis in NVivo. Narrative analysis of transcripts included 330 topics relating to 6 main areas of focus.

Results: Attitudes and views on effective future campaigning reflected a desire for greater social inclusion, but did not focus on prevention and health services. Professionals focused on increasing interpersonal skills, people with dementia on normalization, and carers on awareness-raising.

Conclusions: Public health campaigning and education in relation to dementia, could benefit from closer consideration of perspective and age of recipient in intervention design. Interpersonal skills and social inclusion were identified as key issues.

Key words: dementia, attitude, public health, voice, people with dementia, carer, care, social work, service industry, education

\section{Introduction}

Social attitudes toward dementia are becoming increasingly important as part of a wider shift in emphasis from cure to care. This implies new directions for public health education and campaigning. A number of factors are at play that will influence psychogeriatric practice and that of other helping professionals. First, following the wider disability and mental health survivor

Correspondence should be addressed to: Dr. Irja Haapala, University of Melbourne, School of Social and Political Sciences, Melbourne, Victoria 3010, Australia. Phone: +61-3-8344-2760, +61-438-758-851. Email: irja.haapala@unimelb.edu.au. Received 29 Mar 2018; revision requested 21 Apr 2018; revised version received 3 May 2018; accepted 12 May 2018. First published online 18 July 2018. movements, people with dementia are finding a political voice, which brings that perspective into sharper focus (Swaffer, 2015; Bartlett et al., 2017; Dementia Alliance International, 2017). This suggests not only that professional voices would no longer be the dominant perspective determining service systems and wider public attitudes; it also indicates that the voices of carers and people with dementia should be distinguished from each other (Yeandle et al., 2012). Market distinctions between providers and consumers become more difficult to sustain. Second, a shift toward managing dementia in the community means that it is both more visible in the public domain and that it makes everyday interactions increasingly important in maintaining well-being and social inclusion (Phillipson et al., 
2018). Third, as positive attitudes toward dementia can increasingly shape positive outcomes, public health campaigning should be progressively shifting toward understanding how messages are interpreted in the community (Gerritsen et al., 2016). Current public health approaches have tended to focus on information transmission to raise awareness of dementia as a disease, draw public attention to personal risk and prevention, and while age groups have been identified in their evaluation studies, age has predominantly served as a background variable or to allow for comparison between respondents above and below 60 or 65 years in terms of their understanding of these health-related messages (Léon et al., 2015; Cheston et al., 2016; Miron et al., 2017). Understanding the priorities and reception of public health campaigning and education among different age groups is important for effective intervention design. As we know from empirical studies, it is worthwhile to support the adoption of positive attitudes and healthy lifestyle among all age group because with relatively small changes, we can prevent or stall cognitive impairment and dementia (Kivipelto et al., 2017).

In this study, we have examined two potential factors affecting attitudes toward dementia and the reception of public health messaging: perspective and age. First, we have interviewed persons representing different perspectives, including that of people with dementia, carers and healthcare, social work and service professionals, and second, we have examined the effects of age-group on what they consider to be public health priorities. Throughout the three-year study, we have worked closely with an advisory group representing service providers, carers, and people with dementia. In addition to health and social work professionals, commercial service staff were interviewed at the advisory group's suggestion. Age has been examined in conformity with gerontological research showing that attitudes toward ageing vary by age-group and that these interact with attitudes toward dementia (Behuniak, 2011; Zelig, 2014), often creating negative social perceptions (North and Fiske, 2012) and effects on people's sense of agency (Lamont et al., 2015). Specific age groups may also hold distinctive perspectives on the purpose and meaning of growing old (Tornstam, 2005; Biggs and Lowenstein, 2011; Biggs, 2018). We know less about age group differences in relation to dementia and about appropriate ways to increase public capacity to empathic understanding toward those affected by it.

In this study, we have used dementia as an umbrella term to refer to the different types of progressive neurological conditions affecting the brain (Winblad et al., 2016). While dementias consist of a number of diverse conditions, in the public mind these frequently exist as a common and simplified social category (Cheston et al., 2016).

Each of the factors identified above will cast new challenges to public health interventions and the negotiation of professional and patient role relationships. In previous two papers, we have separately identified perspective and age as important factors in peoples' first impressions of dementia and personal desires were to be personally affected. It was found that closeness to the disease (in terms of family or caring connection) positively influenced perceptions across health, social work and commercial service professionals, plus differences in perspective between carers and persons with dementia (Haapala et al., 2018). Age differences were also found to affect first impressions and empathic understanding (Biggs et al., 2018). In this paper, we examine what different perspectival groups think campaigning itself should prioritize and then re-examine these findings as they are inflected by age. The current paper, then, addresses two main questions: to what extent do different perspectival groups, and age groups within them, have different priorities concerning campaigning in relation to dementia and how should current and future campaigns take this into account?

\section{Methods}

\section{The study}

In this qualitative study, we carried out 111 semistructured interviews among community-living self-selected people (83 women, 28 men) in 5 Australian states (QLD, SA, WA, NSW, and VIC) between March and September 2017 as part of a three-year project (2016-2018) approved by the University of Melbourne Humanities and Applied Sciences Human Ethics Sub-Committee (HESC 1647136).

\section{Participant recruitment}

Participants were recruited via key professional and consumer organizations and with calling cards placed in community-centers, cafes, and shops inviting participation from within the community and from as wide an age range as possible starting with 18 years. The final sample has an age range from 25 years to 87 years (Table 1 ).

For this research, participants were grouped into four age groups, young adults (25-35 years), mid-lifers (36-50 years), later mid-lifers (51-65 years), and older adults (66-87 years), representing five "voices" and five perspective groups: people 
Table 1. Participant characteristics by voice; three professional groups as one and separately by field

\begin{tabular}{|c|c|c|c|c|c|c|c|}
\hline & \multirow[b]{2}{*}{$\begin{array}{l}\text { PEOPLE WITH } \\
\text { DEMENTIA } \\
N=19\end{array}$} & \multirow[b]{2}{*}{$\begin{array}{l}\text { CARERS } \\
N=28\end{array}$} & \multirow[b]{2}{*}{$\begin{array}{l}\text { PROFESSIONALS } \\
N=64\end{array}$} & \multicolumn{3}{|c|}{$\begin{array}{c}\text { PROFESSIONALS } \\
(N=64) \text { BY FIELD }\end{array}$} & \multirow[b]{2}{*}{$\begin{array}{l}\mathrm{ALL} \\
N=111\end{array}$} \\
\hline & & & & $\begin{array}{l}\text { HEALTHCARE } \\
N=21\end{array}$ & $\begin{array}{l}\text { SOCIAL } \\
\text { WORK } \\
N=23\end{array}$ & $\begin{array}{l}\text { SERVICE } \\
N=20\end{array}$ & \\
\hline \multicolumn{8}{|l|}{ Age groups } \\
\hline Younger adults & 0 & 3 & 10 & 5 & 4 & 1 & 13 \\
\hline Mid-lifers & 0 & 2 & 21 & 6 & 8 & 7 & 23 \\
\hline Later mid-lifers & 11 & 15 & 28 & 10 & 9 & 9 & 54 \\
\hline Older adults & 8 & 8 & 5 & 0 & 2 & 3 & 21 \\
\hline \multicolumn{8}{|l|}{ Age, years } \\
\hline Min-Max & $59-87$ & $30-86$ & $25-71$ & $28-62$ & $25-70$ & $33-71$ & $25-87$ \\
\hline Mean & 67.9 & 59.6 & 49.9 & 47.0 & 49.0 & 53.9 & 55.4 \\
\hline $\mathrm{SD}$ & $(7.6)$ & $(13.9)$ & $(11.8)$ & $(11.9)$ & $(13.0)$ & $(9.5)$ & $(13.6)$ \\
\hline \multicolumn{8}{|l|}{ Gender } \\
\hline Male & 13 & 4 & 11 & 1 & 5 & 5 & 28 \\
\hline Female & 6 & 24 & 53 & 20 & 18 & 15 & 83 \\
\hline \multicolumn{8}{|l|}{ Area of residence } \\
\hline Urban & 16 & 21 & 47 & 18 & 17 & 12 & 84 \\
\hline Rural & 1 & 4 & 10 & 3 & 3 & 4 & 15 \\
\hline Regional & 2 & 3 & 7 & 0 & 3 & 4 & 12 \\
\hline \multicolumn{8}{|l|}{ Household income } \\
\hline Low & 7 & 17 & 8 & 1 & 2 & 5 & 32 \\
\hline Average & 9 & 8 & 41 & 13 & 15 & 13 & 58 \\
\hline High & 3 & 3 & 15 & 7 & 6 & 2 & 21 \\
\hline \multicolumn{8}{|l|}{ Educational level } \\
\hline Basic education & 1 & 2 & 0 & 0 & 0 & 0 & 3 \\
\hline Secondary level & 5 & 3 & 6 & 0 & 0 & 6 & 14 \\
\hline Technical degree & 3 & 9 & 11 & 2 & 4 & 5 & 23 \\
\hline Undergraduate & 2 & 7 & 30 & 13 & 12 & 5 & 39 \\
\hline Postgraduate & 8 & 7 & 17 & 6 & 7 & 4 & 32 \\
\hline
\end{tabular}

with dementia $(n=19)$, carers $(n=28)$, and three helping professional groups, i.e. healthcare professionals $(n=21)$, social workers $(n=23)$, and people who worked in service professions $(n=$ 20). Service professions included hairdressers, ITand media consultants, hospitality, and customer service staff.

Participant characteristics presented in Table 1 indicate that the youngest interviewees were in the two professional groups and oldest among people with dementia. Carers were in the middle by age. They were either currently or in the past had been in a carer's role; 14 for their partner, 14 for their parent(s), and sometimes also for another relative. Median time as a carer was 5.5 years, varying from 4 months to over 15 years, and the type of dementia in question also varied, including Lewy Body, frontotemporal, and Alzheimer's disease (AD); ten were caring for a person with young onset dementia. Thirteen of the nineteen interviewees with dementia had been diagnosed with young onset dementia 4-15 years ago (Lewy body, frontotemporal, or unspecified); four with $\mathrm{AD}$ 1-7 years ago and one with vascular dementia and one with suspected Alzheimer's; nine participated with their care partner. The two women with dementia are in the older adults' age group, one with young onset dementia since age 59 years, and the other with $\mathrm{AD}$. We did not ask about medication regimens.

\section{Data collection procedures}

Telephone interviews lasting about an hour were carried out by two interviewers, independently, with frequent debriefing on progress with each other, the project lead and advisory group consisting of seven representatives from the consumer dementia research network. With people with dementia and their care partner, a face-toface interview was arranged as a rule. Couples were interviewed separately, unless by agreement the partner was present at the interview. All participants provided informed consent following the guidelines in National Statement on Ethical Conduct in Human Research, 2007 (Updated May 
Table 2. Coding framework for the question: "What would and effective campaign on dementia look like?"

\begin{tabular}{|c|c|}
\hline $\begin{array}{l}\text { CATEGORY (SECOND } \\
\text { LEVEL THEME) }\end{array}$ & EMERGING THEME (FIRST LEVEL THEME) \\
\hline Awareness raising & $\begin{array}{l}\text { Provide general information on dementia, inform about the variability, types and definitions, } \\
\text { inform about variability of symptoms, provide more information on young onset dementia, } \\
\text { and capture the interest of the public }\end{array}$ \\
\hline $\begin{array}{l}\text { Understanding and } \\
\text { interaction }\end{array}$ & $\begin{array}{l}\text { Increase understanding, over and above awareness raising, show how to help and interact with } \\
\text { people with dementia, show case studies, show real-life stories of people with dementia and } \\
\text { show the family experience of dementia, and show how people can cope with dementia }\end{array}$ \\
\hline Dignity/respect/rights & $\begin{array}{l}\text { Treat people with respect and ensure dignity, remember that people with dementia are still the } \\
\text { same person, the person is still there, don't write them off, people with dementia have a right } \\
\text { to lead a full life and live well, do not pigeonhole them, reduce stigma, advocate for people } \\
\text { with dementia and carers, and provide emotional support for carers }\end{array}$ \\
\hline Normalizing dementia & $\begin{array}{l}\text { Remember that people with dementia are normal people, change the language related to } \\
\text { dementia, normalize the presence of dementia in our lives, promote dementia-friendly } \\
\text { communities, think that it could be you, dementia can affect you, send the message "you are } \\
\text { not alone," show that it is not a terrible terminal disease, make dementia visible, and focus } \\
\text { on the positive }\end{array}$ \\
\hline Prevention methods & $\begin{array}{l}\text { Develop and distribute a tool for screening, donate body and brain to science, promote good } \\
\text { dietary habits, keeping the brain active, and tell people how to adopt healthy lifestyle habits } \\
\text { to prevent or stave off dementia and chronic disease }\end{array}$ \\
\hline $\begin{array}{l}\text { Healthcare system and } \\
\text { services }\end{array}$ & $\begin{array}{l}\text { Explain the care journey (in health and social care), provide information about the services } \\
\text { available, reduce fear of a care home, collaborate on "journey together" attitude campaign } \\
\text { holding hands together including politicians, focus on design and care for safety at home, } \\
\text { and increase financial support for carers and care, especially in rural/regional areas }\end{array}$ \\
\hline
\end{tabular}

2015) (NHMRC, 2015) and the Alzheimer Europe (2011) Report on Ethics for Dementia Research. Each participant received an AU $\$ 40$ voucher to major national retailers.

The two main probe questions posed during the interviews to answer our research question were:

1. "What would an effective campaign on dementia look like?" This question asked about action wanted in the public domain.

2. The question was followed by "Do you have specific target groups or settings in mind for the campaign?”

\section{Data organization, code development, and analysis procedures}

Data from 111 transcripts in Word was imported into NVivo 11. A sample of $40 \%$ of the transcripts was first coded by emerging themes by both interviewers (first and second authors) to ensure inter-coder reliability. Any discrepancies in coding were discussed by the research team and resolved before coding all of the transcripts. This resulted in 330 topics coded under 34 themes. Second round of coding allowed for higher order thematic grouping of the first level codes into six main areas of focus: (1) awareness-raising, (2) increasing understanding and interaction, (3) normalizing dementia, (4) ensuring dignity, respect, and rights (5) prevention methods and (6) improving healthcare systems and services. This "coding framework" is presented in Table 2. Suggestions for target group and settings selection were listed and analyzed by perspective and age group. Validity of this process was supported by researcher triangulation between the two coder-interviewers and principal investigator plus consultation with the advisory group of dementia research consumer network.

Categorized data was extracted and imported into Excel 2016 to produce the descriptive tables and figures. Data is presented as a proportion of expressions within each group and entire sample, calculated as the number of expressions (for suggestions for effective campaign) divided by the total number of expressions within group. On average, each question received between two and three expressions per person. In other words, most interviewees had more than one comment to give on each question.

Analysis of the data was carried out first by perspective and then by age group within perspective. When age and perspective were looked at together, the professional groups were joined as one to achieve larger sample size within age group. Within the carers' group, young adults' and mid-life age groups were also combined to achieve sufficient numbers. 


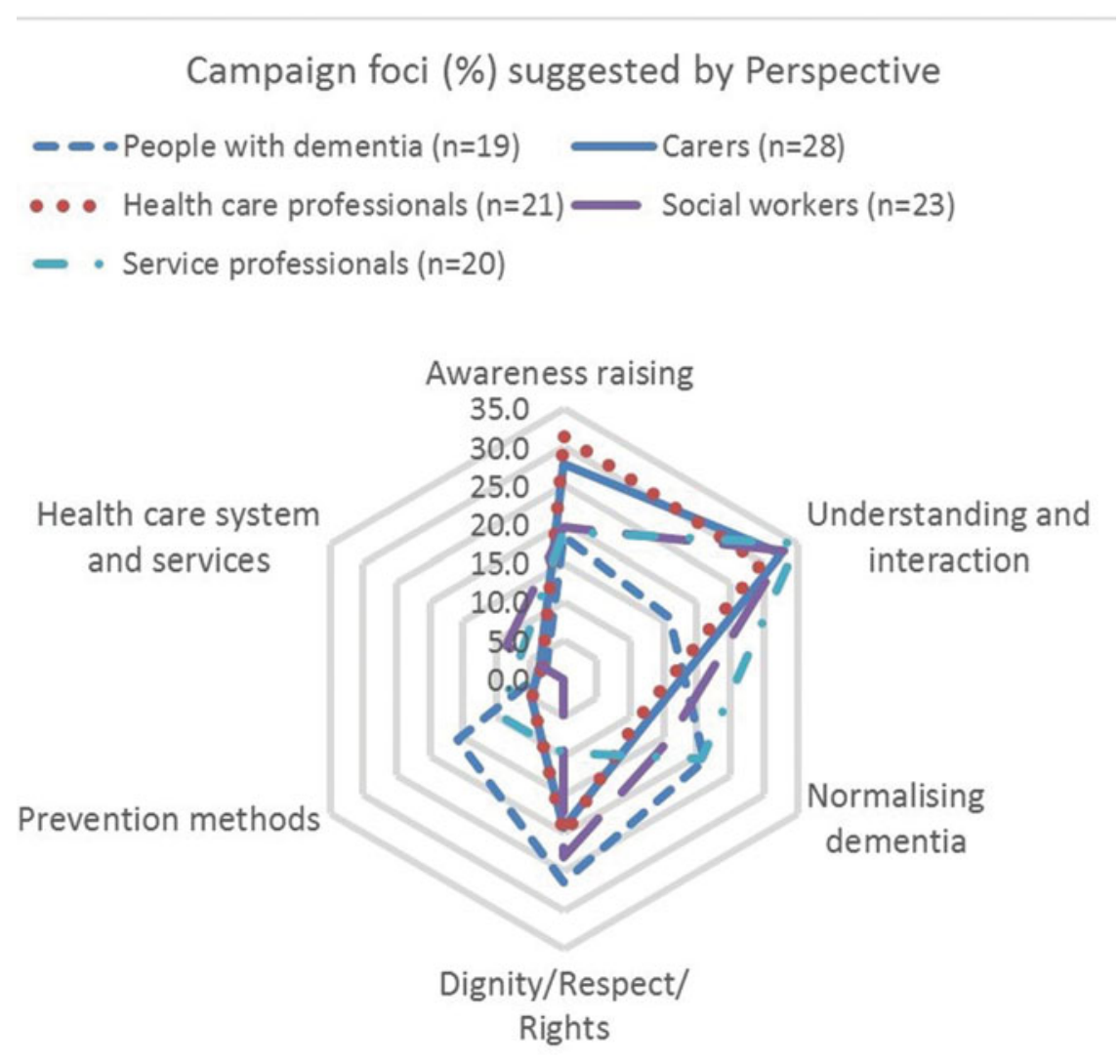

Figure 1. Suggested campaign foci, percentage (\%) of total number of topics within perspective. Figure 1 presents a radar chart of the spread of the topics for campaign under six focus areas by perspective, i.e. people with dementia, carers, and the three professional groups: healthcare professionals, social workers, and service professionals.

\section{Results}

\section{Perspectival views on priorities for effective campaigning in relation to dementia}

Figure 1 presents a radar chart of the spread of the topics for campaign under six focus areas by perspective, i.e. people with dementia, carers, and the three professional groups: healthcare professionals, social workers and service professionals. There are six main points to make on similarities and differences between perspectives.

First, with the exception of people with dementia, priority has been placed on increasing understanding and interaction by all other groups.

Second, there is considerable overlap between the voice of carers and healthcare professionals in focusing on raising awareness, increasing understanding and interaction, and campaigns to secure the dignity, respect, and rights of people with dementia.

Third, people with dementia placed some emphasis on campaigns related to prevention methods and stalling the progression of the condition, but most of all they emphasized campaigns to normalize dementia in the public sphere and to secure the dignity, respect, and rights of people with dementia. This would imply that when examined by perspective, the views of people with dementia differ from the other groups, while the latter are somewhat similar.

Fourth, service professionals and social workers were closer to the emphasis placed by people with dementia on normalizing dementia. While the two also suggested campaigns on awareness-raising and increasing understanding and interaction, they diverged on prevention methods and dignity, respect, and rights issues, with the former mentioned more often by service professionals and the latter by social workers.

Fifth, and most surprisingly, given the emphasis of contemporary public health campaigning, healthcare systems and services were not prioritized by any group, including heathcare professionals.

Finally, when taken together, increasing understanding and interaction and normalizing dementia may represent complementary categories based on perspective. People with dementia may be wishing for social inclusion, while other groups want to know how to interact with them. 


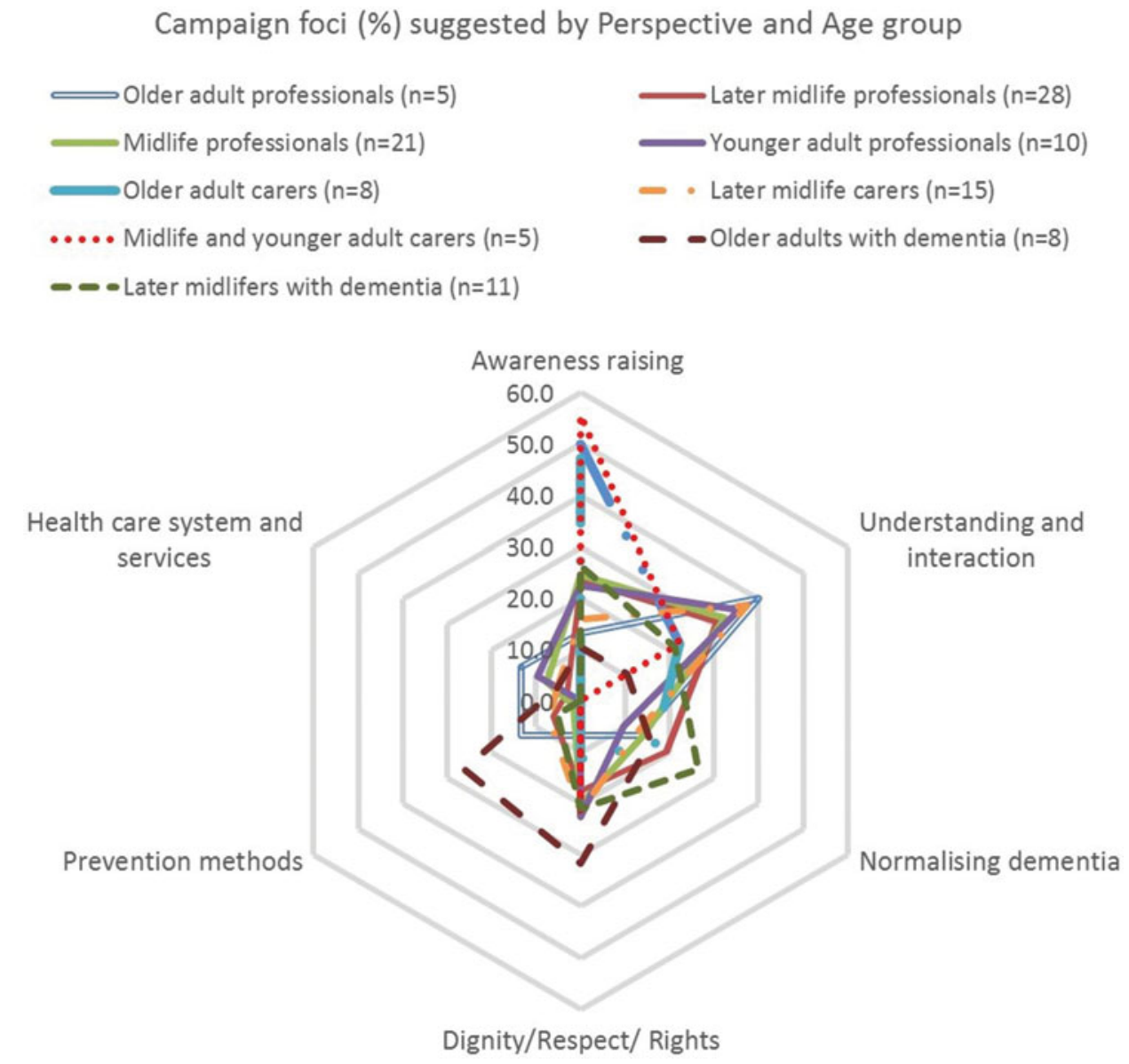

Figure 2. Suggested campaign foci, percentage (\%) of total number of topics by age group within perspective. Figure 2 presents a radar chart of the spread of the topics suggested for campaigns under six main foci by age group within perspective.

\section{Considering age group differences within perspective}

When we combined age group and perspective in our approach, we distinguished differences in emphasis between age groups within perspective. Age was shown to interact with perspective, disaggregating the concerns of particular groups. Figure 2 presents a radar chart of the spread of the topics suggested for campaigns under six main foci by age group within perspective. There are six main points to make:

1. Awareness-raising campaigns were most strongly identified by carers in young adulthood and midlife, plus older adult carers, but rarely by later midlife carers.

2. Understanding and interaction -increasing campaigns were emphasized by all professional age groups regardless of age, plus by later midlife carers. It was less important for other carer age groups and people with dementia.

3. Normalizing dementia appeared as most important to later mid-lifers with dementia, followed by later midlife professionals. It was not emphasized by younger and midlife carers.
4. Dignity, respect, and rights were most emphasized by older adults with dementia, but not by older adult professionals.

5. Prevention methods -related campaigns were most emphasized by older adults with dementia.

6. Healthcare systems and services-related campaigns were not prioritized by any age group or perspective.

In terms of priorities for campaigning, the interactions are complex, but certain trends stand out. Mid-life and older carers preferred awarenessraising, while later mid-life carers did not. They emphasized understanding and interaction. This latter trend was most aligned to professional groups regardless of age, who were almost uniform in their aggregated sense of priority. Age distinguished people with dementia, with older adults emphasizing prevention, followed by dignity and rights, but not normalizing, which was favored by mid-lifers.

It would appear, then, that when professional groups were aggregated, their professional status was reflected in their category emphasis. However, this centered on a need to increase understanding 
and interaction skills with people with dementia, rather than prevention or service issues. Where services were prioritized, this was among the younger and older adults rather than midlifers although the emphasis remained low and differences small. Carers and people with dementia, not only showed different patterns of priority, their prioritizing reflected age group differences. The split between increasing understanding interaction and normalizing dementia was most marked between professionals and later mid-lifers with dementia, with older people showing little interest in either. As with perspective alone, this may have reflected a complementary set of perspectives centered around social inclusion.

\section{Target groups suggested for campaigning}

While the most often suggested target for public health campaigning in relation to dementia, was the general public, mentioned by 98 of the interviewees, there were differences in emphasis between the perspectives: people with dementia and carers suggested adopting a universal approach and targeting the general public $(60.9 \%$ and $64.3 \%$ of the suggestions) somewhat more often than adopting a selective settings approach, i.e. targeting families, communities, schools, work places or sectors, or specific age groups. All three professional groups, on the other hand, more often emphasized a selective (settings or age groups) approach (varying from $53.8 \%$ to $59.0 \%$ ). From within the selective approach, unlike the other perspectival groups, service professionals emphasized an age group specific approach over the settings approach.

\section{Discussion}

In this paper, we have examined the narratives of 111 people interviewed about their views on public health campaigning and education in relation to dementia. We have addressed two main questions: to what extent does different perspectival and age groups have different priorities and how should current and future campaigns take this into account? Three main issues are discussed.

First, a major topic of concern identified by professionals and some carers was the need to increase everyday understanding and skills to positively interact with people within the public sphere. This dovetails with a desire to normalize dementia, particularly voiced by people with dementia and commercial service professionals. Normalizing reflects a wish to see dementia as a normal part of everyday life (as distinct from a normal part of ageing) and thus facilitate forms of social engagement and inclusion. It may, however, lead to confusion around messages that present dementia as exclusively a disease process, aimed to differentiate it from normal processes of ageing or something that increases with age. While this may point to a more nuanced communication through public health interventions, it speaks of two sides of the same trend, to forge an empathic bridge that would enable people with dementia to age in a place, remain socially included and stay engaged with society. It would appear from these findings that dementia is not so much associated with stigma, as an embarrassed absence of interaction skills in public spaces. This suggests a way to counter negative attitudes, including stigma in relation to dementia (Herrmann et al., 2018), with a considered approach to address the upskilling needs of the public. Recent dementiafriendly community projects, such as the Kiama project in Australia (Phillipson et al., 2018) have made good progress in this regard.

Second, healthcare services and prevention are not seen as a priority for campaigning from any perspective or by any age group. However, this has been the principal focus of interventions on attitude change to date. This might mean that these messages have been accepted and public awareness has moved on, although studies mentioned earlier would cast doubt on this conclusion. It may mean that perceptions are catching up with the shift away from cure toward coping and maintenance (Livingston et al., 2017; Prince, 2017). Whatever the underlying trend, this finding identifies a potential mismatch between those sending public health messages and those now receiving them. As such, the priorities of the current group of participants differ in important ways from three priorities set by the WHO (2016) of understanding the disease, health service priorities, and preventative measures.

Third, that the views of healthcare consumers should not be lumped together, and fall into distinctive groups, by perspective and by age is re-emphasized by the current research. Indeed, while age played little role in the changing perceptions of professionals, it did when comparing these two groups. It indicates first that those who use services should be categorized less by market position and more by their relationship to the disease in question. Carers and people with dementia emerge as separate voices. Carers would appear to specifically emphasize awareness-raising, perhaps reflecting a sense of continued public misunderstanding and neglect of the problem. Including age as a variable, while muted in its effects, evidences a source of diversity which requires further analysis. Age is an important 
variable in identifying priorities related to dementia desired of public health messaging and therefore its successful reception. This study reinforces findings (Biggs et al., 2018), which have showed that empathic understanding of dementia appears to vary by age group. While younger adults in that study showed a form of distanced empathy, mid-lifers saw the other from a predominantly cognitive viewpoint, and later mid-lifers as another encountered in practical communication. Older adults exhibited a set of attitudes closer to their self-identity and based on interaction with others. These differences indicate the importance of a shift in emphasis for public health intervention from assessing the reception of pre-defined messages, to an awareness of where recipients are in terms of age-based priorities. While more extensive study is called for, age should be considered an important element in the perception of dementia and how messages are responded to.

Validity of our findings is supported by the large number of interviews and the volume of data, computer-assisted data coding and analysis, involvement of two collaborating researchers in data collection, triangulation between three researchers in data coding, analysis and interpretation of results, plus an active consumer advisory group in consultation throughout the study. As a limitation, our sample comprised predominantly women (Table 1) and the age group categories within perspective were skewed in so far as people with dementia only populated later midlife and older adults age groups, while professionals were most likely to be in midlife or later midlife with very few younger adults. Although this demographic may not be too far from reality in the field, it weakens the capacity to extrapolate our findings to younger adult age groups.

In terms of our two main questions: different age groups within perspectival groups have similar priorities among professional groups, but distinguish between both carers and people with dementia. Future campaigning in relation to dementia should recognize the expressed need for socially inclusive measures, most specifically normalizing dementia into daily life and the enhancing of interpersonal skills among professionals and others.

The current findings would suggest that a continuing shift toward the co-creation of public health campaigning and education is justified. It is important to include the voice of people with dementia, which in two recent reviews by Cole et al. (2018) and Conway et al. (2018) has been shown to be lacking in intervention and research design. People's needs for non-pharmacological, needs-addressing, and psychosocial interventions are likely to vary not only by type of dementia, as pointed out by Cohen-Mansfield (2018), but also by age. Considering perspective and age difference in the reception of messages might provoke a rethink of how campaigns are targeted, taking the position of the recipient more explicitly into account. That attitudes are moving toward increasing understanding and interaction skills and normalizing dementia in the service of greater social inclusion, may form an important new direction of future campaigning and professional education.

\section{Conflict of interest}

None.

\section{Description of authors' roles}

I. Haapala drafted the paper and led the analysis of the data. All three authors have equally participated in writing the paper. I. Haapala and A. Carr collected, coded, and analyzed the data in discussion with S. Biggs and the advisory group. $\mathrm{S}$. Biggs as the principal investigator devised the overall strategy for the research.

\section{Acknowledgments}

We would like to thank all our interviewees for giving their time and sharing their stories and insight with us. We are also thankful to the research network coordinating organization, the Cognitive Decline Partnership Centre, members of Dementia Australia's National Consumer Network, Carers Victoria, the Brotherhood of Saint Laurence, and the funding organizations for their support and for facilitating the recruitment process in five Australian states. This project is funded through the Cognitive Decline Partnership Centre (CDPC; http://sydney.edu.au/medicine/cdpc/) receiving support from the Australian National Health and Medical Research Council (NHMRC grant Id: 9100000) and partners including Brightwater Care Group, Dementia Australia, Hammond Care and Helping Hand Aged Care.

\section{References}

Bartlett, R., Windemuth-Wolfson, L., Oliver, K. and Dening, T. (2017). Suffering with dementia: the other side of "living well". International Psychogeriatrics, 29, 177-179.

Behuniak, S. (2011). The living dead? The construction of people with Alzheimer's disease as zombies. Ageing and Society, 31, 70-92.

Biggs, S. (2018). Negotiating ageing: Cultural adaptation to the prospect of a long life. London: Routledge. 
Biggs, S., Haapala, I. and Carr, A. (2018). Generational perceptions of dementia: age, othering and generational intelligence. In G. McDonald and J. Mears (eds.), Dementia as Social Experience: Valuing Life and Care (Chapter 5). London: Routledge.

Biggs, S. and Lowenstein, A. (2011). Generational Intelligence: A Critical Approach to Age Relations. New York, NY: Routledge.

Cheston, R., Hancock, J. and White, P. (2016). A cross-sectional investigation of public attitudes toward dementia in Bristol and South Gloucestershire using the approaches to dementia questionnaire, International Psychogeriatrics, 28, 1717-1724.

Cohen-Mansfield, J. (2018). Non-pharmacological interventions for persons with dementia: what are they and how should they be studied? International Psychogeriatrics, 30, 281-283. doi:10.1017/S104161021800039X

Cole, L., Samsi, K. and Manthorpe, J. (2018). Is there an "optimal time" to move to a care home for a person with dementia? A systematic review of the literature. International Psychogeriatrics. Epublished ahead of print. doi:10.1017/S1041610218000364.

Conway, E. R., Watson, B., Tatangelo, G. and McCabe, M. (2018). Is it all bleak? A systematic review of factors contributing to relationship change in dementia. International Psychogeriatrics. Epublished ahead of print. doi: $10.1017 /$ S1041610218000303.

Dementia Alliance International. (2017). Available at: http://www.dementiaallianceinternational.org/; last accessed 29 March 2018.

Gerritsen, D. L., Oyebode, J. and Gove, D. (2016). Ethical implications of the perception and portrayal of dementia. Dementia. Epublished ahead of print. doi: 10.1177/1471301216654036.

Haapala, I., Carr, A. and Biggs, S. (2018). What would I want? Dementia perspectives and priorities amongst people with dementia, family carers and service professionals? International fournal of Care and Caring. in press

Herrmann, L. et al. (2018). A systematic review of dementia-related stigma research: can we move the stigma dial? The American fournal of Geriatric Psychiatry, 26, 316-331.

Kivipelto, M., Mangialasche, F. and Ngandu, T. (2017). Can lifestyle changes prevent cognitive impairment? The Lancet Neurology, 16, 338-339.

Lamont, R. A., Swift, H. J. and Abrams, D. (2015). A review and meta-analysis of age-based stereotype threat: negative stereotypes, not facts, do the damage. Psychology and Aging, 30, 180.
Léon, C., Pin, S., Kreft-Jais, C. and Arwidson, P. (2015). Perceptions of Alzheimer's disease in the French population. Fournal of Alzheimer's Disease, 47, 467-478.

Livingston, G. et al. (2017). Dementia prevention, intervention, and care. The Lancet, 390, 2673-2734. doi: $10.1177 / 1471301218754455$.

Miron, A. M., McFadden, S. H., Hermus, N. J., Buelow, J., Nazario, A. S. and Seelman, K. (2017). Contact and perspective taking improve humanness standards and perceptions of humanness of older adults and people with dementia: a cross-sectional survey study. International Psychogeriatrics, 29, 1701-1711.

NHMRC. (2015). National Statement on Ethical Conduct in Human Research (2007) (Updated May 2015) Section 4: Ethical Considerations Specific to Participants. Chapter 4.5: People with Cognitive Impairment, an Intellectual Disability, or a Mental Illness. Canberra: Australian Government. National Health and Medical Research Council.

North, M. S. and Fiske, S. T. (2012). An inconvenienced youth? Ageism and its potential intergenerational roots. Psychological Bulletin, 138, 982.

Phillipson, L. et al. (2018). Involvement of people with dementia in raising awareness and changing attitudes in a dementia friendly community pilot project. Dementia, DOI: 10.1177/1471301218754455

Prince, M. (2017). Progress on dementia-leaving no one behind. The Lancet, 390, e51-e53.

Swaffer, K. (2015). Dementia and prescribed disengagement $^{\mathrm{TM}}$. Dementia, 14, 3-6. doi: 10.1177/1471301214548136

Tornstam, L. (2005). Gerotranscendence: A Developmental Theory of Positive Aging. New York, NY: Springer Publishing Company.

WHO. (2016). WHO Global Action Plan on the Public Health Response to Dementia 2017-2025. Geneva, Switzerland: World Health Organisation.

Winblad, B. et al. (2016). Defeating Alzheimer's disease and other dementias: a priority for European science and society. The Lancet Neurology, 15, 455-532.

Yeandle, S., Kröger, T. and Cass, B. (2012). Voice and choice for users and carers? Developments in patterns of care for older people in Australia, England and Finland. Fournal of European Social Policy, 22, 432-445.

Zelig, H. (2014). Dementia as a cultural metaphor. The Gerontologist, 54, 258-267. 